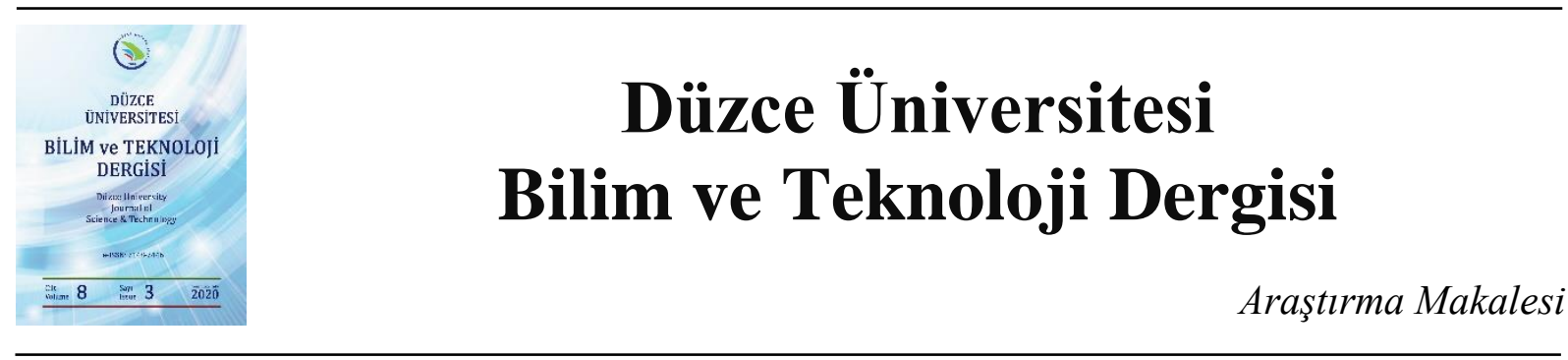

\section{R134a'ya Alternatif Bir Soğutucu Akışkan (R513A) Kullanan Buhar Sıkıştırmalı Soğutma Sistemlerinin Enerji ve Çevresel Analizi}

\author{
Abdullah YILDIZ ${ }^{\mathrm{a}}$, (D) Ragip YILDIRIM ${ }^{\mathrm{a}, \mathrm{b}^{*}}$ \\ ${ }^{a}$ Makine Mühendisliği Bölümü, Mühendislik Fakültesi, Uşak Üniversitesi, Uşak, TÜRKIYYE \\ ${ }^{b}$ Elektrik ve Enerji Bölümü, Bucak Emin Gülmez Teknik Bilimler Meslek Yüksekokul, Burdur Mehmet Akif Ersoy \\ Üniversitesi, Burdur, TÜRKIYE \\ * Sorumlu yazartn e-posta adresi: ryildirim@mehmetakif.edu.tr \\ DOI : 10.29130/dubited.690197
}

\begin{abstract}
ÖZET
Küresel ısınma Dünya gündeminin ana konularından birisidir. Dolayısıyla, soğutucu akışkanların çevresel etkilerini azaltmak için birçok çalışma ve düzenleme yapılmaktadır. Çevre dostu soğutucu akışkanların kullanılması soğutucu akışkanların çevre üzerinde olumsuz etkisinin azaltılması için gereklidir. Düşük küresel ısınma potansiyeline (GWP) sahip HFC/HFO soğutucu akışkan karışımları HFC soğutucu akışkanların yerini aldığ düşünülmekte ve son zamanlarda ticari olarak üretilmektedirler. Bu çalışmada, R134a ve R513A soğutucu akışkanlarının performansları teorik olarak incelenmiştir. Ayrıca soğutucu akışkanların çevresel etki değerlendirilmesi yaşamsal döngü iklim performansına (LCCP) göre incelenmiştir. Soğutucu akışkanların enerji performansları farklı evaporatör $\left(-15\right.$ ile $2.5^{\circ} \mathrm{C}$ arasında) ve kondenser $\left(30\right.$ ve $\left.35^{\circ} \mathrm{C}\right)$ sıcaklıkları için yapılmış̧ır. Evaportaör sıcaklığı $-15^{\circ} \mathrm{C}$ ve kondenser sicaklığ $130^{\circ} \mathrm{C}$ iken R134a ve R513A'nın COP değerleri sirasıyla 3.87 ve 3.77'dir. Aynı kondenser sıcaklı̆ğ için evaporatör sıcaklı̆g $12.5{ }^{\circ} \mathrm{C}$ olduğunda R134a ve R513A'nın COP değerleri sırasıyla 7.28 ve 7.16 olmaktadır. Dolaysıyla R134a ve R513A'nın COP değerlerinin hemen hemen benzer olduğu söylenebilir. R513A'nın GWP oranı R134a'nın yaklaşık yarısı kadardır. Dolayısıyla R513A R134a'dan \%56 oranında daha az direkt emisyon (DE) değerine sahip olduğu görülmüştür. Her iki soğutucu akışkanın toplam emisyon değerinin büyük bir çoğunluğu (R134a için \%94.98, R513A için \%96.77) sistemin enerji tüketiminden kaynaklanmaktadır. R513A soğutucu akışkanın yanıcılık özelliğinin yoktur ayrıca doğrudan R134a ile çalışan sistemde herhangi bir değişiklik yapmadan kullanılabilir. R513A yukarıda saydığımız özelliklerden dolayı R134a'ya alternatif olarak kullanılabilir.
\end{abstract}

Anahtar Kelimeler: Küresel ısınma potansiyeli, İklim değişikliği, $\mathrm{CO}_{2}$ emisyonu, Yaşam döngüsü iklim performanst (LCCP), R513A

\section{Energy and Environmental Analysis of Vapor Compression Refrigeration Systems Using an Alternative Refrigerant (R513A) to R134a}

\section{ABSTRACT}

Global warming is one of the main topics of the world agenda. Therefore, many studies and arrangements are made to reduce the environmental effects of refrigerants. The use of environmentally friendly refrigerants is necessary to reduce the negative impact of refrigerants on the environment. HFC / HFO refrigerant mixtures with 
low global warming potential (GWP) are thought to replace HFC refrigerants and have been produced commercially recently. In this study, the performances of R134a and R513A refrigerants are theoretically investigated. In addition, environmental impact assessment of refrigerants has been examined according to the life cycle climate performance (LCCP). Energy performances of refrigerants have been made for different evaporator (between -15 and $2.5^{\circ} \mathrm{C}$ ) and condenser $\left(30\right.$ and $35^{\circ} \mathrm{C}$ ) temperatures. While evaporator temperature is $-15{ }^{\circ} \mathrm{C}$ and condenser temperature is $30{ }^{\circ} \mathrm{C}$, the COP values of $\mathrm{R} 134 \mathrm{a}$ and $\mathrm{R} 513 \mathrm{~A}$ are 3.87 and 3.77 respectively. When the evaporator temperature is $2.5^{\circ} \mathrm{C}$ and condenser temperature is $30{ }^{\circ} \mathrm{C}$, the COP values of R134a and R513A are 7.28 and 7.16, respectively. Therefore, the COP values of R134a and R513A are almost similar. The GWP ratio of R513A is about half of R134a. Therefore, it has been observed that R513A has 56\% less direct emission (DE) value than R134a. The majority of the total emission value of both refrigerants ( $94.98 \%$ for R134a, $96.77 \%$ for R513A) is due to the energy consumption of the system. The COP value of R513A refrigerant is almost the same as R134a and the total emission (LCCP) value of R513A is lower than R134a. R513A refrigerant does not have flammability, and it can be used directly in the system working with R134a without any changes. R513A can be used as an alternative to R134a due to the features mentioned above.

Keywords: Global warming potential, Climate change, $\mathrm{CO}_{2}$ emission, Life cycle climate performance (LCCP), R513A

\section{GİRIS}

İklim değişikliğinin çevre üzerinde etkilerinden dolayı bitki ve canlıların yaşamını olumsuz etkilemektedir. Buhar sıkıştırmalı sistemler iklim değişikliğine neden olan faktörlerden birisidir. Bunların en başında hidroflorokarbonlar (HFC) soğutucu akışkan kullanan buhar sıkıştırmalı soğutma sistemleri gelmektedir. 1990'lı yıllardan beri gelişmiş ülkelerde kullanılan soğutma sistemlerinde yüksek küresel ısınma potansiyeline sahip soğutucu akışkanlar kullanılmaktadır. $\mathrm{Bu}$ soğutucu akışanların sızıntı yoluyla atmosfere salınması nedeniyle iklim değişikliği üzerinde etkisi büyüktür [12].

Soğutma ve iklimlendirme sistemleri uygulamalarında HFC soğutucu akışkanların iklim değişikliği üzerinde olumsuz etkilerini azaltmak için bazı düzenlemeler yapılmıştır (Montreal protokolü ve Kyoto protokolü) [3]. Son 20 yılda, soğutucu akışkanların piyasasında en çok florlu sera gazına sahip HFC'lerin hakim olmuştur. HFC'lerin yüksek GWP oranına sahip olması nedeniyle Avrupa Birliği 517/2014 yılında çıkarılan tüzük ile önümüzdeki 15 yılda pazarlanacak toplam miktarının önemli derecede azaltılması planlanmaktadır. Bu düzenleme ile ilk olarak 2015 yılından itibaren GWP oranı 150'nin üzerinde olan HFC'lerin ev tipi buzdolaplarında kullanılması yasaklanmıştır [2]. İklim değişikliğinin olumsuz sonuçlarını ortadan kaldırmak için yapılan bu düzenlemeler HFC soğutucu akışkanların fiyatlarını arttırdı. Bu yüzden, soğutucu akışkan endüstrisi düşük GWP oranına sahip, ekonomik ve çevresel açıdan sürdürülebilir alternatif soğutucu akışkanlar için araştırma yapmaktadırlar [4-5].

Hidrofloroolefinler (HFO) grubunda yer alan R1234yf ve R1234ze soğutucu akışkanlar R134a'ya alternatif olarak geliştirilmiştir. R1234yf'nin soğutma sisteminde kullanılmasının enerji performansını iyileştirmediği, R1234ze'nin kullanılması sistemde değişiklikleri ihtiyaç duyulduğu yapılan çeşitli teorik ve deneysel çalışmalarla kanıtlanmıştır [6-8]. HFO'ların bu olumsuz özelliklerini ortadan kaldırmak için HFC ve HFO'ların belirli oranla karıştırılması ile elde edilen çeşitli soğutucu akışkanlar geliştirilmektedir. Bu soğutucu akışkan karışımları mekanik olarak ayrılmayan bir bileşene sahiptir [9-10].

Son günlerde HFC/HFO karışımlarından oluşan R513A soğutucu akışkanı geliştirilmiştir. R513A soğutucu akışkanı R134a/R1234yf' nin kütlesel olarak yüzde 44/56 oranında karıştırılmasından oluşur. R513A azeotropik bir karışımdır. Ozon delme potansiyeli sıfırdır (ODP) ve GWP oranı (573) R134a'ya göre \%50 oranında daha azdır. Ayrıca, R513A soğutucu akışkanın yanıcılık özelliği yoktur. 
Bu özellikleri sayesinde Montreal Protokolü'ndeki limitleri karşılamaktadır. R513A soğutucu akışkan R134a'ya benzer şekilde ASHRAE tarafından toksik olmayan ve yanmayan akışkan (A1) gurubunda sınıflandırılmıştır. R134a ve R513A'nın genel özellikleri Tablo 1'de görülmektedir [11]. Akışkanların termofiziksel özelleri Refprop programından alınarak soğutucu akışkanlara ait basınç-entalpi diyagramı (Şekil 1) ve basınç sıcaklık grafiği çizilmiştir (Şekil 2).

Tablo 1. R134a ve R513A'nın genel özellikleri[11]

\begin{tabular}{|c|c|c|}
\hline Soğutucu akıșkan & R134a & R513A \\
\hline Bileşim & Saf & R134a/R1234yf 44/56 \\
\hline ODP & 0 & 0 \\
\hline GWP & 1300 & 573 \\
\hline Kritik sıcaklık $\left[{ }^{\circ} \mathrm{C}\right]$ & 101.1 & 97.7 \\
\hline Kritik basınç $[\mathrm{kPa}]$ & 4059.3 & 3855.3 \\
\hline Kaynama Noktasi $\left[{ }^{\circ} \mathrm{C}\right]$ & -24.6 & -29.9 \\
\hline Sıv1 yoğunluğu$*\left[\mathrm{~kg} / \mathrm{m}^{3}\right]$ & 1295.3 & 1222.4 \\
\hline Buhar yoğunluğ $\mathrm{u}^{*}\left[\mathrm{~kg} / \mathrm{m}^{3}\right]$ & 14.35 & 17.14 \\
\hline $\mathrm{S}_{1 V 1} \mathrm{C}_{\mathrm{p}} *\left[\mathrm{~kJ} / \mathrm{kg}{ }^{\circ} \mathrm{C}\right]$ & 1.341 & 1.313 \\
\hline Buhar $\mathrm{C}_{\mathrm{p}} *\left[\mathrm{~kJ} / \mathrm{kg}{ }^{\circ} \mathrm{C}\right]$ & 0.897 & 0.920 \\
\hline S1v1 1s1 iletim katsayıs1* $\left[\mathrm{W} / \mathrm{m}^{\circ} \mathrm{C}\right]$ & 92.08 & 79.26 \\
\hline S1v1 1s1 iletim katsayıs1* $\left[\mathrm{W} / \mathrm{m}^{\circ} \mathrm{C}\right]$ & 11.50 & 11.72 \\
\hline S1v1 viskozite*[Pa s] & 267 & 227.5 \\
\hline Buhar viskozite*[Pa s] & 10.7 & 10.5 \\
\hline
\end{tabular}

$* 0{ }^{\circ} \mathrm{C} ' \mathrm{de}$

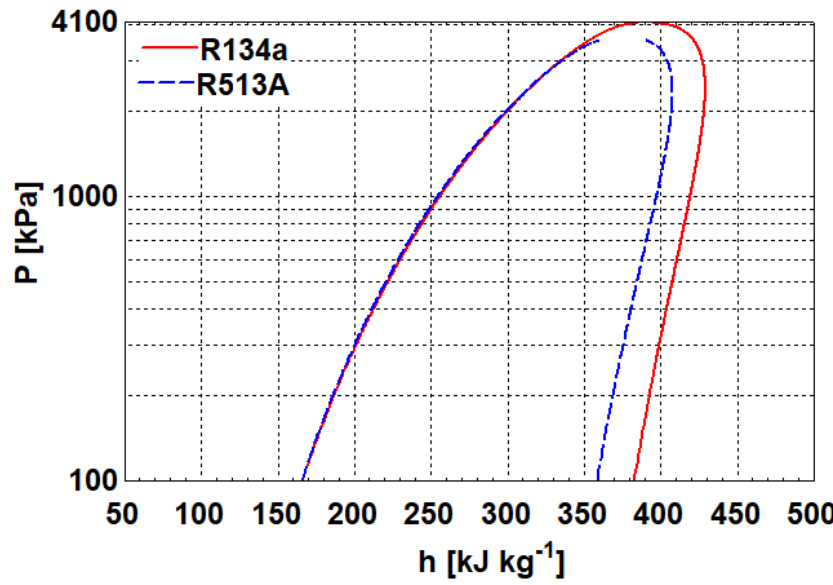

Şekil 1. R134a ve R513A soğutucu akışkanların basınç-entalpi diyagramı

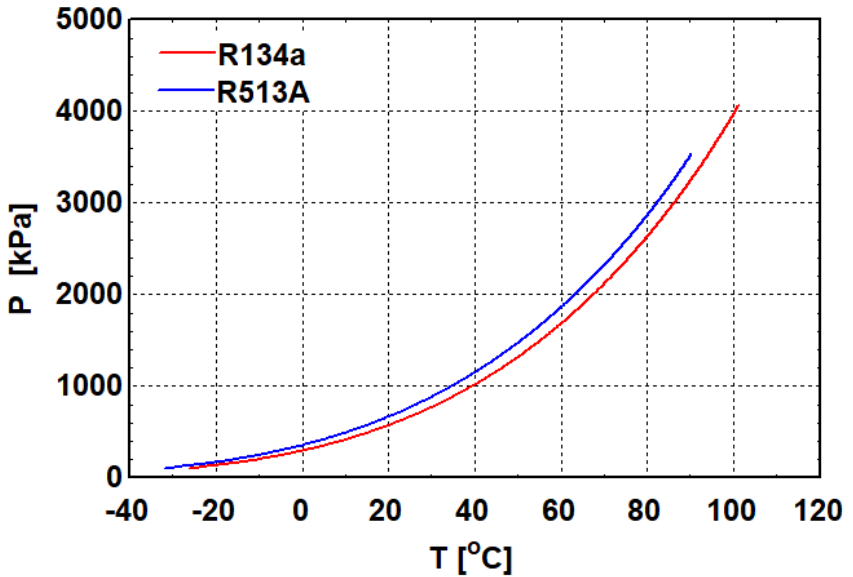

Şekil 2. R134a ve R513A soğutucu aklşkanların basınç-slcaklık grafiği 
Mota-Babiloni vd. [11] deneysel çalışmalarında R513A soğutucu akışkanın R134a soğutucu akışkanına alternatife olarak kullanılmasını incelemişlerdir. Her iki akışkan için karşılaştırma yapabilmek için aynı çalışma şartları altında test etmişlerdir. R513A soğutucu akışkanın R134a'dan daha iyi performans gösterdiğini ve R513A'nın daha yüksek soğutma kapasitesine sahip olduğunu açıklamışlardır. Diğer bir çalışmalarında Mota-Babiloni vd. [12] R513A ve R134a soğutucu akışkanların ekserji analizini deneysel olarak incelemişlerdir. Her iki soğutucu akışkan için aynı şartlar altın yaptıkları deneysel çalışma sonucunda, en yüksek ekserji kaybının kompresörde daha sonra evaporatörde olduğunu belirtmişlerdir. R513A'nın ekserji verimin R134a'dan \%0.4 daha fazla olduğunu ve genel olarak termodinamiğin ikinci yasasına göre R513A'nın R134a'nın yerini kullanılabilir olduğunu açıklamışlardır. Llopis vd. [13] R134a'ya alternatif olan yeni nesil soğutucu akışkanları (R513A ve R450A) deneysel incelemişlerdir. Deneysel sonuçlarının değerlendirmesini kompresörün 24 saat boyunca enerji tüketimine göre yapmışlardır. R513A ve R450A soğutucu akışkanların enerji tüketimi R134a'dan fazla olduğunu ancak sera gazı emisyonunun düşmesinde etkili olduklarını belirtmişlerdir.

Meng vd. [14] arabaların klima sistemlerinde R134a/R1234yf (kütlesel olarak 11/89) soğutucu akışkan karışımının hem 1sıtma hem de soğutma performansını deneysel olarak incelemişlerdir. R134a/R1234yf soğutucu akışkan karışımın soğutma COP değeri R134a'dan \%4 ile \%9 oranında daha düşük olduğunu belirtmişlerdir. Isıtma durumunda R134a/R1234yf soğutucu akışkan karışımının COP değeri R134a ile kıyaslandığında ise bu oran \%4 ile \%16 arasında değiştiğini ifade etmişlerdir. Ayrıca R1234yf soğutucu akışkanına \%11 oranında R134a eklenmesi ile elde edilen karışımın yanıcılık özelliğinin ortadan kalktığını belirtmişlerdir. Böylece elde edilen karışımın hem yanıcılık özelliği yok hem de çevre dostu (ODP $=0$ ve GWP <150) bir akışkan olduğunu açıklamışlardır. Dolayısıyla bu soğutucu akışkan karışımı araç soğutma sisteminde R134a'ya alternatif akışkan olarak kullanılabileceğini ifade etmişlerdir. Aprea vd. [15] ev tipi buzdolabında R134a, R1234yf ve R134a/R1234yf (kütlesel olarak 10/90) soğutucu akışkanların performansını deneysel olarak incelemiş ve karşı1laştırmışlardır. R134a/R1234yf soğutucu akışkanın R134a ile termofiziksel olarak benzer davranışlar gösterdiğini belirtmişlerdir. R134a/R1234yf soğutucu akışkan karışımı R134a'ya göre \%16, R1234yf'ye göre \%14 daha az enerji tükettiğini ifade etmişlerdir. Başka bir çalışmada Aprea vd. [16] R134a, R1234yf, R1234ze(E), R134a/R1234yf (kütlesel olarak 10/90), R134a/R1234ze (E) (kütlesel olarak 10/90) gibi düşük GWP oranına sahip soğutucu akışkanlar arasında enerji ve çevresel analizini deneysel olarak incelemişlerdir. R134a/R1234yf (kütlesel olarak 10/90) soğutucu akışkan karışımı R134a'ya göre \%17 oranında emisyon değerini azalttı̆̆ını belirtmişlerdir. Lee vd. [17] yaptıkları deneysel çalışmada $\% 5, \% 10$ ve $\% 15 \mathrm{R} 134 \mathrm{a}$ içeren üç farklı R134a/ R1234yf soğutucu akışkan karışımını kullanmışlardır. R1234yf ve R134a/R1234yf karışımlarının COP, 1sıtma kapasitesi, soğutma kapasitesi ve deşarj sıcaklıkları R134a soğutucu akışkanı ile yakın sonuçlar verdiğini belirtmişlerdir. R1234yf ve R134a/R1234yf karışımları R134a'dan daha fazla soğutucu akışkan şarjı yapılması gerektiğini (yaklaşık olarak \%11) vurgulamışlardır.

Dünya genelinde yeni nesil soğutucu akışkanların buhar sıkıştırmalı sistemlerinde daha düşük GWP oranına sahip çalışma akışkanı olarak kabul edilmesi ve uygulanması öncesinde bu akışkanın davranışları hakkında daha fazla araştırma yapılması gerekmektedir. Bu soğutucu akışkanların, yapılan ufak modifikasyonlarla R134a ile çalışan sistemlerle uyumlarının bilinmesi çok önemlidir. $\mathrm{Bu}$ çalışmada, R134a ve R513A soğutucu akışkanların enerji analizi teorik olarak incelenmiştir. R513A soğutucu akışkanı soğutma ve iklimlendirme sistemlerinde R134a'nın yerini aldığı düşünülmektedir. Ancak, konuyla ilgili literatürü incelediğimizde sınırlı sayıda çalışma vardır. Ayrıca literatürde bulunan çalışmalardan farklı olarak R134a ve R513A soğutucu akışkanların çevresel etkisi yaşam döngüsü iklim performansı (LCCP) analizine göre incelenmiştir. Düşük GWP oranına sahip yeni nesil soğutucu akışkanlar üzerine araştırma yapmak gerekli ve önemlidir. Dolayısıyla bu çalışma literatüre önemli katkılar sunacaktır. 


\section{MATERYAL VE METOT}

Bu çalışmada, R134a ve R513A soğutucu akışkanların performansları karşılaştırmak için tek kademeli buhar sıkıştırmalı soğutma sistemi kullanılmıştır (Şekil 3). Soğutma sistemi için yapılan kabuller Tablo 2'de görülmektedir. Ayrıca borularda basınç kaybının olmadığı, sistemin bütün elemanları sürekli acık akışlı olduğu kabul edilmiştir.

Tablo 2. Sistem için yapılan kabuller

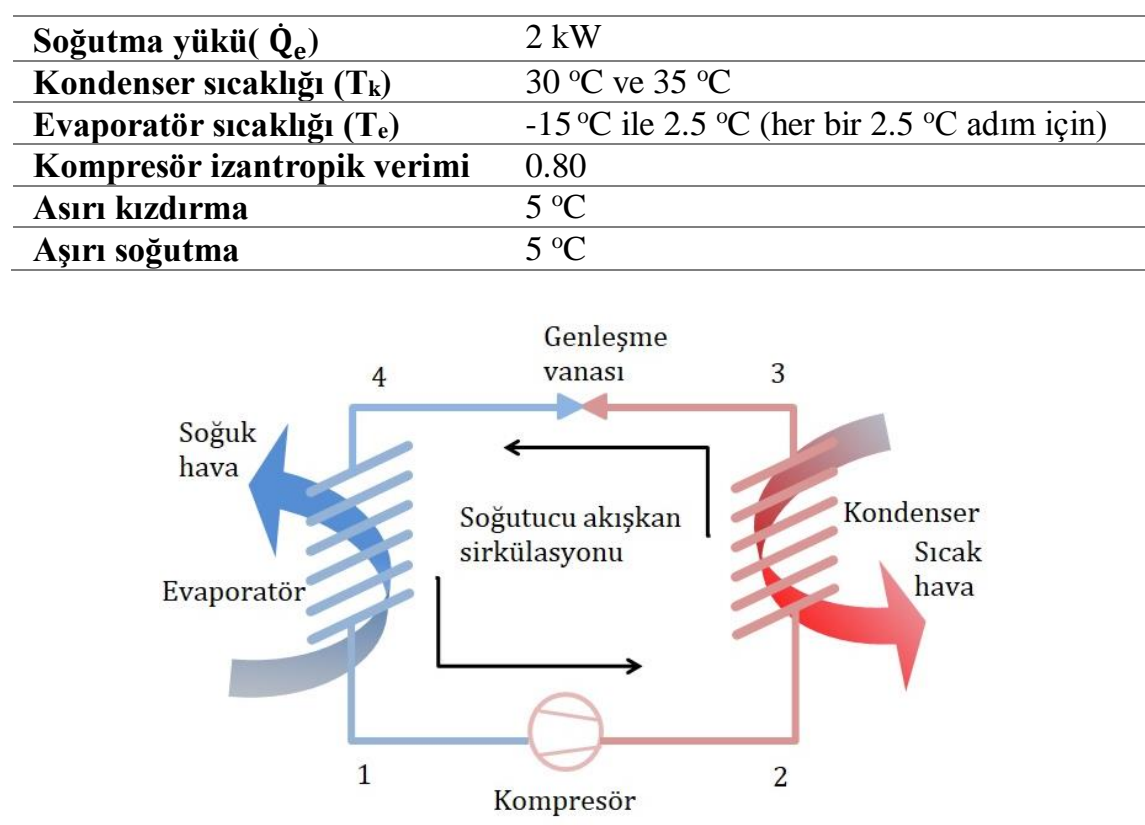

Şekil 3. Tek kademeli buhar sıkıştırmalı soğutma çevriminin şematik görünümü

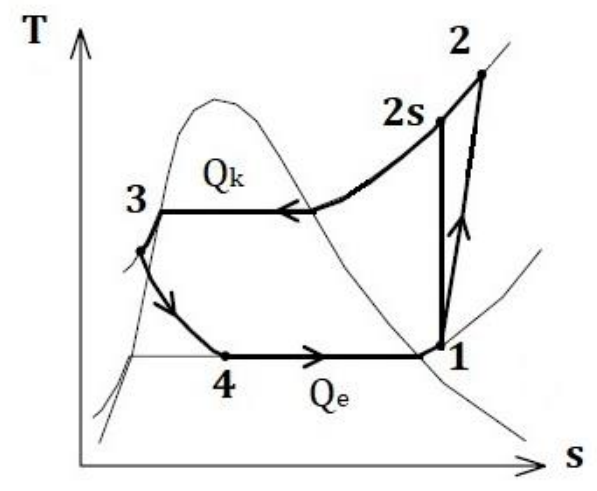

Şekil 4. Tek kademeli buhar sıkıştırmalı soğutma çevrimine ait T-s diyagramı

\section{A. ENERJİ ANALİí}

Tek kademeli buhar sıkıştırmalı soğutma çevriminin enerji analizi termodinamiğin birinci yasasına göre yapılmıştır. Şekil 3 ’te verilen soğutma sisteminin elemanlarına ait enerji denge denklemleri aşağıda verilmiştir.

Kompresörün harcadığı enerji Eşitlik 1 ile hesaplanabilir.

$\dot{\mathrm{W}}_{\mathrm{k}}=\dot{\mathrm{m}}_{\mathrm{sa}}\left(\mathrm{h}_{2}-\mathrm{h}_{1}\right)$ 
Kondenserden atılan 1sı Eşitlik 2 ile bulunabilir.

$\dot{\mathrm{Q}}_{\mathrm{k}}=\dot{\mathrm{m}}_{\mathrm{sa}}\left(\mathrm{h}_{2}-\mathrm{h}_{3}\right)$

Evaporatörün soğutma kapasitesi Eşitlik 3 ile hesaplanabilir.

$\dot{\mathrm{Q}}_{\mathrm{e}}=\dot{\mathrm{m}}_{\mathrm{sa}}\left(\mathrm{h}_{1}-\mathrm{h}_{4}\right)$

Soğutma sistemine ait performans kat sayısı (COP) Eşitlik 4'te verilmiştir.

$\mathrm{COP}=\frac{\dot{\mathrm{Q}}_{\mathrm{e}}}{\dot{\mathrm{W}}_{\mathrm{k}}}$

Hacimsel soğutma kapasitesi (VCC) soğutma sistemini değerlendirmek için önemli parametrelerdir. Hacimsel soğutma kapasitesi Eşitlik 5’ten hesaplanır [18].

$\operatorname{VCC}=\rho_{1}\left(\mathrm{~h}_{1}-\mathrm{h}_{4}\right)$

Yukarıda verilen eşitliklerde (Eşitlik 1-5), h ilgili referans numarası ile gösterilen entalpi değerini $(\mathrm{kJ} / \mathrm{kg})$ göstermektedir. $\dot{\mathrm{m}}_{\mathrm{sa}}$ soğutucu akışkan debisini $(\mathrm{kg} / \mathrm{s}), \rho_{1}$ emme hattı yoğunluğunu $\left(\mathrm{kg} / \mathrm{m}^{3}\right)$ belirtmektedir.

\section{B. YAŞAM DÖNGÜSÜ İKLIM PERFORMANSI (LCCP)}

Soğutucu akışkanların çevresel etkisi yaşam döngüsü iklim performansı (life cycle climate performance (LCCP)) analizine göre yapıldı. LCCP analizi temelde toplam eşdeğer isınma etkisi (Total Equvalent warming impact (TEWI)) gibidir. Ancak LCCP analizi daha kapsamlıdır. LCCP bir sistemin ömrü boyunca (beşikten mezara kadar) tüm emisyonları içerir. LCCP analizi aşağıdaki gibi hesaplanır [19]:

$$
\begin{aligned}
& \mathrm{LCCP}=\text { Direkt emisyonlar }(\mathrm{DE})+\text { Endirekt emisyonlar(EE) } \\
& \mathrm{DE}=\mathrm{C}(\mathrm{L} \text { ALR }+\mathrm{EOL})\left(\mathrm{GWP}+\mathrm{GWP}_{\mathrm{adp}}\right) \\
& \mathrm{EE}=\mathrm{L} \text { AEC EM }+\Sigma(\mathrm{m} \mathrm{MM})+\Sigma\left(\mathrm{m}_{\mathrm{r}} \mathrm{MM}\right)+\mathrm{C}(1+\mathrm{L} \text { ALR }) \mathrm{RFM}+\mathrm{C}(1-\mathrm{EOL}) \mathrm{RFD}
\end{aligned}
$$

Eşitlik 6'de görüldüğü gibi direkt emisyonlar, ünitenin kullanım ömrü boyunca atmosfere salınan soğutucunun etkilerinden oluşur (sızıntılardan kaynaklanan yıllık soğutucu kaybı, ünitenin kullanım ömrü sonunda soğutucu akışkan kaybı, atmosferdeki soğutucu akışkanın parçalanmasından kaynaklanan atmosferik reaksiyon ürünleri vb.) [19-20].

Endirekt emisyonlar, ünitenin ömrü boyunca kullanılmasından kaynaklanan emisyonları içerir. Bunlar şunlardır [19-20]:

- Elektrik üretiminden kaynaklanan emisyonlar

- Malzeme üretiminde kaynaklanan emisyonlar

- Soğutucu akışkanların üretiminden kaynaklanan emisyonlar

- Ünitenin kullanım ömrü sonrası elden çıkarılmasından kaynaklanan emisyonlar

Eşitlik 6 - 8'de C soğutucu akışkan şarj miktarını (kg), L soğutma ünitesi çalışma ömrünü (yıl), ALR yıllık soğutucu akışkan şarj oranını (soğutucu akışkan şarjının \%), EOL cihaz ömrü sonunda soğutucu akışkan sızıntı oranı (soğutucu akışkan şarjının \%), GWP küresel ısınma potansiyelini $\left(\mathrm{kgCO}_{2} / \mathrm{kg}\right)$, $\mathrm{GWP}_{\text {adp }}$ atmosferdeki soğutucu akışkanın bozulmasından kaynaklanan küresel ısınma potansiyelini $\left(\mathrm{kgCO}_{2} / \mathrm{kg}\right)$, AEC yıllık enerji tüketimini $(\mathrm{kWh} / \mathrm{y} 1 \mathrm{l})$, EM Elektrik üretimi emisyon değeri $\left(\mathrm{kgCO}_{2} / \mathrm{kWh}\right)$, m soğutma ünitesinin kütlesini $(\mathrm{kg}), \mathrm{MM}$ malzeme üretim emisyonunu $\left(\mathrm{kgCO}_{2} / \mathrm{kg}\right), \mathrm{m}_{\mathrm{r}}$ 
geri dönüştürülen malzemenin kütlesini $(\mathrm{kg}), \mathrm{RM}$ geri dönüştürülen malzemenin emisyonunu $\left(\mathrm{kgCO}_{2} / \mathrm{kg}\right)$, RFM soğutucu akışkan üretim emisyonunu $\left(\mathrm{kgCO}_{2} / \mathrm{kg}\right)$, RFD soğutucu akışkanın bertarafından kaynaklanan emisyonu $\left(\mathrm{kgCO}_{2} / \mathrm{kg}\right)$ göstermektedir.

Çalışmada kullanılan soğutucu akışkanlara ait GWP, GWP adp ve üretim emisyon değerleri ve Tablo 3 te verilmiştir. LCCP analizi için gerekli olan referans değerleri Tablo 4'de verilmiştir. Elektrik tüketiminden kaynaklanan emisyon değerini hesaplayabilmek için elektrik santrali üretim emisyon değeri gereklidir. Literatürde birçok ülke için ortalama emisyon değeri vardır. Türkiye için bu değer $0.523 \mathrm{kgCO}_{2} / \mathrm{kWh}$ olarak alınmıştır [21].

Tablo 3. Soğutucu aklşkanlara ait GWp, GWPadp ve Soğutucu akışkan üretim emisyon değerleri

\begin{tabular}{llll}
\hline Soğutucu akışkan & GWP & GWP $_{\text {adp }}$ & RFM \\
\hline R134a & 1300 & 1.60 & 5.0 \\
\hline R513A & 573 & 2.55 & 9.87 \\
\hline
\end{tabular}

Malzeme üretiminden kaynaklanan emisyonların hesab1 uluslararası soğutma enstitüsünün (International Institute of Refrigeration (IIR)) standartlarına göre yapılmıştır. Soğutma sistemlerinde yaygın olarak kullanılan dört malzeme ve bu malzemelerin iklimlendirme sisteminde ortalama yüzdesi Tablo 4'te verilmiştir. Ayrıca bu malzemelerin hem üretim hem de geri dönüşüm emisyon değerleri verilmiştir [19].

Tablo 4. Soğutma ünitesini oluşturan malzemeler ve bu malzemelerine ait üretim ve geri dönüşüm emisyon değerleri

\begin{tabular}{lcccc}
\hline Malzeme & $\begin{array}{c}\text { Sistemde } \\
\text { bulunma oranı } \\
(\boldsymbol{\%})\end{array}$ & $\begin{array}{c}\text { Üretim emisyon } \\
\text { değeri (kgCO2/kg) }\end{array}$ & $\begin{array}{c}\text { Geri } \\
\text { dönüştürülebilir } \\
\text { oran }(\%)\end{array}$ & $\begin{array}{c}\text { Geri dönüşüm } \\
\text { emisyon değeri } \\
\left(\mathbf{k g C O}_{2} / \mathbf{k g}\right)\end{array}$ \\
\hline Çelik & 46 & 1.8 & 29 & 0.54 \\
\hline Alüminyum & 12 & 12.6 & 67 & 0.63 \\
\hline Bakır & 19 & 3 & 40 & 2.46 \\
\hline Plastik & 23 & 2.8 & 7 & 0.12 \\
\hline
\end{tabular}

Yaşam döngüsü iklim performans analizi $-15{ }^{\circ} \mathrm{C}$ evaporatör sıcaklığ 1 ve $35^{\circ} \mathrm{C}$ kondenser sıcaklığı ve Tablo 5 'te verilen referans değerleri için yapılmıştır.

Tablo 5. Soğutma ünitesi referans değerleri

\begin{tabular}{lll}
\hline Açıklama & Değer & Birim \\
\hline Soğutma kapasitesi & 1 & $\mathrm{~kW}$ \\
\hline Soğutucu akışkan & R134a ve R513A & - \\
\hline Sistemin çalışma ömrü & 15 & $\mathrm{y} 1$ \\
\hline Sitemin şarj miktarı (C) & 1 & $\mathrm{~kg}$ \\
\hline Yıllık soğutucu akışkan sızıntı oranı (ALR) & 2.5 & $\%$ \\
\hline Cihaz ömrü sonunda soğutucu akışkan sızıntı oranı (EOL) & 15 & $\%$ \\
\hline Soğutma ünitesinin kütlesi (m) & 100 & $\mathrm{~kg}$ \\
\hline
\end{tabular}

\section{ARASTIRMA BULGULARI}

\section{A. ENERJI ANALIZII SONUÇLARI}

Teorik analiz sonucunda elde edilen, soğutucu akışkan debisi, kompresör enerji tüketimi, COP ve hacimsel soğutma kapasitesi Şekil 5'te görülmektedir. 
Soğutucu akışkan debisi, soğutucu akışkanın yoğunluğuna, kompresörün geometrik yapısına ve kompresörün izentropik verimine bağlıdır. Şekil 5'te görüldüğü gibi R513A soğutucu akışkanı R134a'dan daha yüksek soğutucu akışkan debisine sahip olduğu görülmektedir. $30^{\circ} \mathrm{C}$ kondenser sıcaklığında R513A'nın soğutucu akışkan debisi 6.94 ile $7.51 \mathrm{gr} / \mathrm{s}$ arasında değişirken R134a'nın soğutucu akışkan debisi 5.88 ile 6.28 gr/s arasında değişmektedir. Dolayısıyla R513A, R134a'dan $\% 18$ ile \%20 oranında daha fazla soğutucu akışkan debisine sahiptir. Teorik olarak bu beklenen bir sonuçtur. Çünkü R513A'nın buhar yoğunluğu R134a'dan yüksektir. Tablo 1'de görüldüğü gibi, R513A ve R134a'nın buhar yoğunluğu sirasıyla 14.14 ve $14.35 \mathrm{~kg} / \mathrm{m}^{3}$ 'tür. Yani R513A'nın yoğunluğu R134a'dan \%19 daha fazladır.

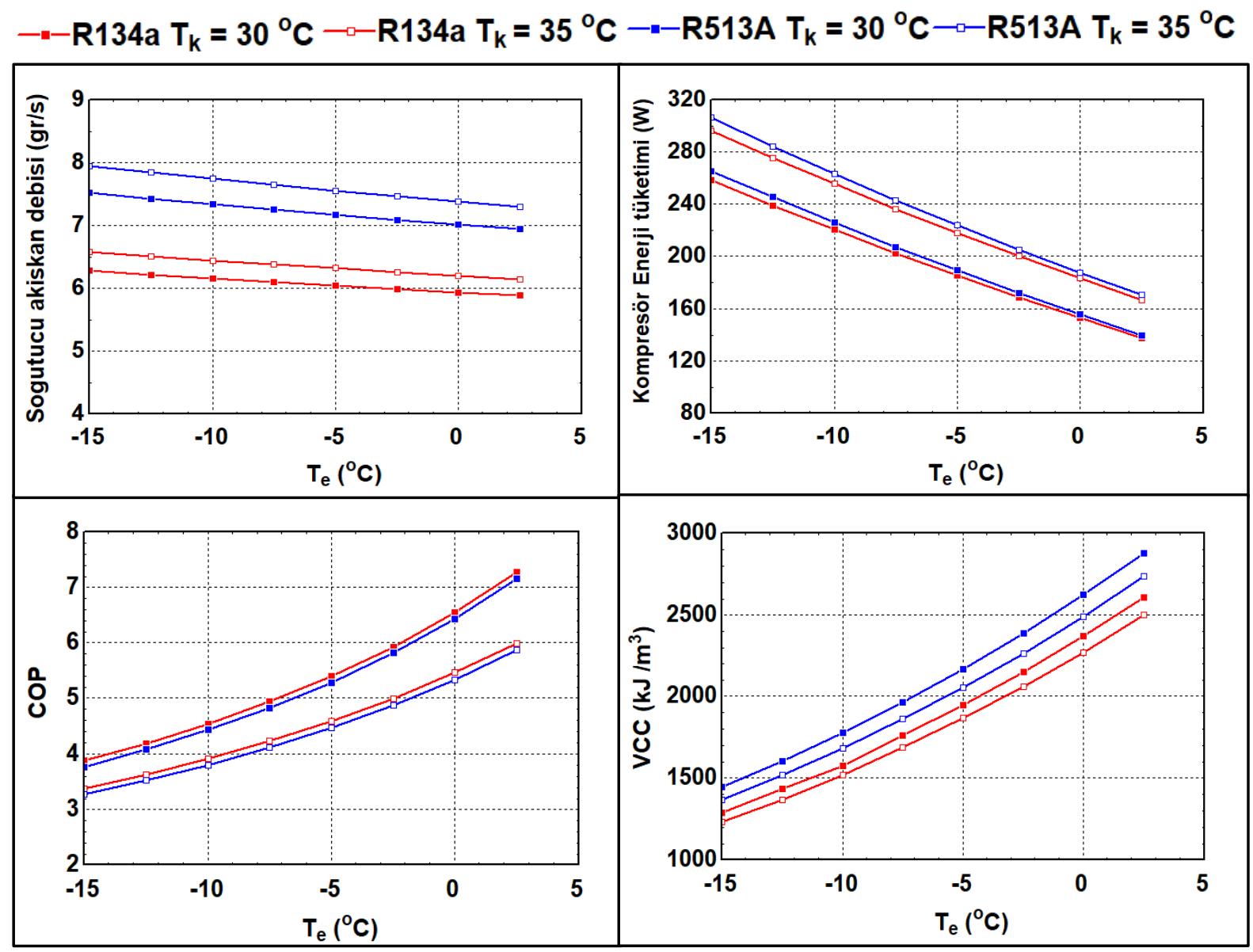

Şekil 5. Soğutucu aklşkanların soğutucu akışkan debisi, kompresör enerji tüketimi, COP ve hacimsel soğutma kapasitelerinin karşılaştırılması

Kompresör enerji tüketimi soğutma sisteminin performans katsayısını (COP) etkileyen parametrelerden birisidir (Eşitlik 4). Soğutma kapasitesini kompresör enerji tüketimine böldüğümüzde elde edilen COP Şekil 5'te görülmektedir. R513A soğutucu akışkanın kompresör enerji tüketimi R134a'dan yüksektir. $30^{\circ} \mathrm{C}$ kondenser sicaklığında R513A'nın kompresör enerji tüketimi 140 ile 266 W arasındadır. R134a'nın ise 137 ile $259 \mathrm{~W}$ arasındadır. R134a ile karşılaştırıldığında R513 A \%2 ile $\% 3$ oranında daha fazla kompresör enerji tüketimine sahiptir.

Soğutucu akışkanların COP değerlerini inceldiğimizde hemen hemen benzer olduğu görülmektedir. Örneğin, $30{ }^{\circ} \mathrm{C}$ yoğuşma sicaklığında ve $-15{ }^{\circ} \mathrm{C},-10{ }^{\circ} \mathrm{C},-5{ }^{\circ} \mathrm{C}$ ve $0{ }^{\circ} \mathrm{C}$ evaporatör sicakliklarında R513A'nın COP değeri sırasıyla 3.77, 4.43, 5.28 ve 6.43'tür. Aynı şartlar altında R134a'nın COP değeri sirasıyla $3.87,4.53,5.40$ ve 6.54 'tür.

Soğutucu akışkanların soğutma etkisine baktığımız zaman (evaporatör entalpi farkı) R134a'nın daha yüksek soğutma etkisine sahip olduğu görülmektedir (Şekil 1). Ancak soğutucu akışkanlar arasında 
karşılaştırma yapmak için soğutucu akışkanların hacimsel soğutma kapasitesine bakmak gerekir (Eşitlik 5). Şekil 5'te verilen çalışma şartlarında altında soğutucu akışkanların hacimsel soğutma kapasitesi görülmektedir. $30{ }^{\circ} \mathrm{C}$ yoğuşma sıcaklığında ve $-15{ }^{\circ} \mathrm{C},-10{ }^{\circ} \mathrm{C},-5{ }^{\circ} \mathrm{C}$ ve $0{ }^{\circ} \mathrm{C}$ evaporatör sicaklıklarında R513A'nın hacimsel soğutma kapasitesi sırasıyla 1447, 1777, 2165 ve $2621 \mathrm{~kJ} / \mathrm{m}^{3}$ 'tür. Aynı şartlar altında R134a'nın hacimsel soğutma kapasitesi sırasıyla 1288, 1576, 1949 ve 2370 $\mathrm{kJ} / \mathrm{m}^{3}$ 'tür tür. Genel olarak baktığımızda R513A R134a'dan daha yüksek hacimsel soğutma kapasitesine (yaklaşık olarak \%10 ile \%12) sahip olduğu görülmektedir. Buradan da anlaşıldığı üzere R513A'nın kompresör enerji tüketimi fazla olmasına rağmen R134a ile benzer COP değerlerine sahip olmasının nedeni hacimsel soğutma kapasitesidir.

\section{B. YAŞAM DÖNGÜSÜ İKLİM PERFORMANSI ANALİZİ SONUÇLARI}

Soğutucu akışkanlar için yapılan yaşam döngüsü iklim performansı analizi Tablo 6 ve Şekil 6'da verilmiştir. Tablo 5'te verilen sonuçları incelediğimizde, R513A soğutucu akışkanı R134a'dan \%56 oranında daha az direkt emisyon (DE) değerine sahip olduğu görülmektedir. Soğutucu akışkanların direkt emisyon değeri toplam emisyonun değerinin çok küçük yüzdelik dilimine karşıllk gelmektedir. Örneğin R134a'nın direkt emisyon değeri toplam emisyon değerinin \%3.19'na karş1lı gelirken, R513A'da \%1.39'na karşıllk gelmektedir. Dolayısıyla soğutucu akışkanların emisyon değerlerinin büyük bir oranı endirekt emisyonlardan oluşmaktadır. Dolaylı emisyonların önemli bir kısmı enerji tüketiminden kaynaklanmaktadır. Bu yüzden, emisyonları azaltmanın en etkili yolu, soğutma sistemlerinin enerji verimliliğini arttırmaktır. Soğutucu akışkanların toplam emisyon değeri (LCCP) karşılaştırıldığında R513A R134a'dan \%1.5 oranında daha yüksek emisyon değerine sahip olduğu görülmüştür.

Tablo 6. Soğutucu akışkanların yaşam döngüsü iklim performansının karşılaştırılması

\begin{tabular}{lcccc}
\hline \multirow{2}{*}{ Emisyon kategorileri } & \multicolumn{2}{c}{ R134a } & \multicolumn{2}{c}{ R513A } \\
\cline { 2 - 5 } & $\begin{array}{c}\text { Emisyon } \\
\text { kgCO }\end{array}$ & $\begin{array}{c}\text { Toplam } \\
\text { emisyondaki } \\
\text { oranı (\%) }\end{array}$ & $\begin{array}{c}\text { Emisyon } \\
\text { kgCO2 }\end{array}$ & $\begin{array}{c}\text { Toplam } \\
\text { emisyondaki } \\
\text { oranı (\%) }\end{array}$ \\
\hline Direkt emisyon (DE) & $\mathbf{6 8 3 . 3 4}$ & $\mathbf{3 . 1 9}$ & $\mathbf{3 0 1 . 9 3}$ & $\mathbf{1 . 3 9}$ \\
\hline Yıllık soğutucu akışkan sızıntısı & 488.10 & 2.28 & 215.67 & 0.99 \\
\hline $\begin{array}{l}\text { Cihaz ömrü sonunda soğutucu akışkan } \\
\text { sıııntısı }\end{array}$ & 195.24 & 0.91 & 86.27 & 0.40 \\
\hline Endirekt Emisyon(EE) & $\mathbf{2 0 7 5 4 . 9 8}$ & $\mathbf{9 6 . 8 1}$ & $\mathbf{2 1 4 5 9 . 2 1}$ & $\mathbf{9 8 . 6 1}$ \\
\hline Soğutucu akışkan üretimi & 6.88 & 0.03 & 13.57 & 0.06 \\
\hline Malzeme geri dönüşüm & 31.00 & 0.14 & 31.00 & 0.14 \\
\hline Malzeme üretimi & 355.40 & 1.66 & 355.40 & 1.63 \\
\hline Enerji tüketimi & 20361.70 & 94.98 & 21059.23 & 96.77 \\
\hline LCCP & $\mathbf{2 1 4 3 8 . 3 2}$ & - & $\mathbf{2 1 7 6 1 . 1 4}$ & - \\
\hline
\end{tabular}




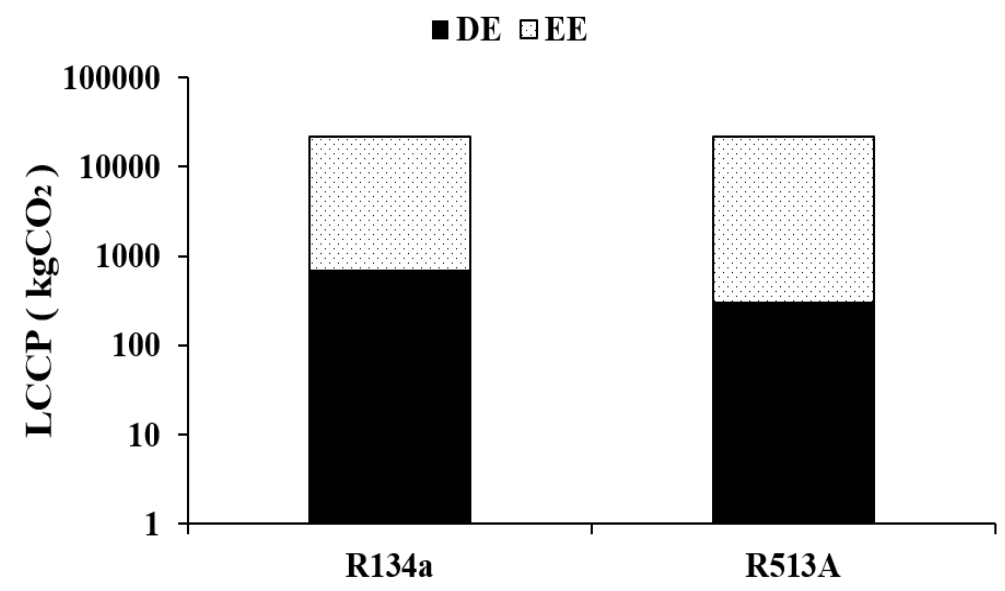

Şekil 6. Soğutucu akışkanların yaşam döngüsü iklim performansının karşılaştırılması

\section{IV.SONUC}

Bu çalışmada R134a ve düşük GWP oranına sahip R513A soğutucu akışkanlarının enerji analizi teorik olarak incelenmiştir. Ayrıca soğutucu akışkanların çevresel etkisini karşılaştırmak için yaşam döngüsü iklim performans analizi yapılmıştır. R134a'ya alternatif olan R513A soğutucu akışkanının GWP oranı R134a'nın yarısı, ODP potansiyeli bulunmamakta ve yanıcılık özelliği yoktur. Yapılan çalışma sonucunda elde edilen sonuçlar şunlardır:

- R513A soğutucu akışkanı R134a'dan daha yüksek soğutucu akışkan debisine sahiptir. Çünkü R513A emme hatt1 yoğunluğu R134a'dan yüksektir.

- R513A soğutucu akışkanın R134a'dan daha yüksek kompresör enerji tüketimine sahiptir. Ancak her iki akışkanın COP değerleri hemen hemen benzer olduğu görülmüştür. Bunun nedeni, R513A'nın hacimsel soğutma kapasitesi R134a'dan yüksek olmasındandır.

- Her iki akışkanın direkt emisyon değerleri toplam emisyon değeri ile karşılaştırıldığında çok küçük olduğu görülmüştür.

- Soğutucu akışkanların endirekt emisyon değerlerinin büyük çoğunluğu enerji tüketiminden kaynaklanmaktadır. Dolayısıyla soğutma sisteminin enerji veriminin arttırılması emisyon değerinin azalması için gereklidir.

\section{KAYNAKLAR}

[1] A. Mota-Babiloni, "Analysis of low global warming potential fluoride working fluids in vapour compression systems. Experimental evaluation of commercial refrigeration alternatives," Universitat Politècnica de València, Valencia (Spain), 2016.

[2] S. Bobbo et al., "Energetic and Exergetic Analysis of Low Global Warming Potential Refrigerants as Substitutes for R410A in Ground Source Heat Pumps," Energies, vol. 12, no. 18, p. 3538, Sep. 2019.

[3] H. Ozcan, "Performance determination of alternative refrigerants by usingexergy method," Karabük University, 2011. 
[4] Z. Yang and X. Wu, "Retrofits and options for the alternatives to HCFC-22," Energy, vol. 59. Elsevier Ltd, pp. 1-21, 15-Sep-2013.

[5] G. Li, M. Eisele, H. Lee, Y. Hwang, and R. Radermacher, "Experimental investigation of energy and exergy performance of secondary loop automotive air-conditioning systems using low-GWP (global warming potential) refrigerants," Energy, vol. 68, pp. 819-831, Apr. 2014.

[6] A. Mota-Babiloni, J. Navarro-Esbrí, Á. Barragán, F. Molés, and B. Peris, "Drop-in energy performance evaluation of R1234yf and R1234ze(E) in a vapor compression system as R134a replacements," Appl. Therm. Eng., vol. 71, no. 1, pp. 259-265, Oct. 2014.

[7] B. Feng, Z. Yang, and R. Zhai, "Experimental study on the influence of the flame retardants on the flammability of R1234yf," Energy, vol. 143, pp. 212-218, Jan. 2018.

[8] C. Zilio, J. S. Brown, G. Schiochet, and A. Cavallini, "The refrigerant R1234yf in air conditioning systems," Energy, vol. 36, no. 10, pp. 6110-6120, 2011.

[9] D. A. Didion and D. B. Bivens, "Role of refrigerant mixtures as alternatives to CFCs," Int. J. Refrig., vol. 13, no. 3, pp. 163-175, 1990.

[10] M. Höbberg and T. Berntsson, "Non-azeotropic mixtures as working fluids in two-stage economizer-type heat pumps," Int. J. Refrig., vol. 17, no. 6, pp. 417-429, 1994.

[11] A. Mota-Babiloni, P. Makhnatch, R. Khodabandeh, and J. Navarro-Esbrí, "Experimental assessment of R134a and its lower GWP alternative R513A," Int. J. Refrig., vol. 74, pp. 680686, Feb. 2017.

[12] A. Mota-Babiloni, J. M. Belman-Flores, P. Makhnatch, J. Navarro-Esbrí, and J. M. BarrosoMaldonado, "Experimental exergy analysis of R513A to replace R134a in a small capacity refrigeration system," Energy, vol. 162, pp. 99-110, Nov. 2018.

[13] R. Llopis, D. Sánchez, R. Cabello, J. Catalán-Gil, and L. Nebot-Andrés, "Experimental analysis of R-450A and R-513A as replacements of R-134a and R-507A in a medium temperature commercial refrigeration system," Int. J. Refrig., vol. 84, pp. 52-66, Dec. 2017.

[14] Z. Meng, H. Zhang, M. Lei, Y. Qin, and J. Qiu, "Performance of low GWP R1234yf/R134a mixture as a replacement for R134a in automotive air conditioning systems," Int. J. Heat Mass Transf., vol. 116, pp. 362-370, 2018.

[15] C. Aprea, A. Greco, and A. Maiorino, "An experimental investigation of the energetic performances of HFO1234yf and its binary mixtures with HFC134a in a household refrigerator," Int. J. Refrig., vol. 76, pp. 109-117, 2017.

[16] C. Aprea, A. Greco, and A. Maiorino, "HFOs and their binary mixtures with HFC134a working as drop-in refrigerant in a household refrigerator: Energy analysis and environmental impact assessment," Appl. Therm. Eng., vol. 141, pp. 226-233, 2018.

[17] Y. Lee, D. G. Kang, and D. Jung, "Performance of virtually non-flammable azeotropic HFO1234yf/HFC134a mixture for HFC134a applications," Int. J. Refrig., vol. 36, no. 4, pp. 1203-1207, 2013.

[18] L. Zhang, J. Zhao, L. Yue, H. Zhou, and C. Ren, "Cycle performance evaluation of various R134a/hydrocarbon blend refrigerants applied in vapor-compression heat pumps," Adv. Mech. Eng., vol. 11, no. 1, 2019.

[19] IIR, "Guideline for Life Cycle Climate Performance," 2016. 
[20] S. Choi, J. Oh, Y. Hwang, and H. Lee, "Life cycle climate performance evaluation (LCCP) on cooling and heating systems in South Korea," Appl. Therm. Eng., vol. 120, pp. 88-98, 2017.

[21] B. Atilgan and A. Azapagic, "Assessing the Environmental Sustainability of Electricity Generation in Turkey on a Life Cycle Basis," Energies, vol. 9, no. 1, p. 31, 2016. 